\title{
DEBRIDEMENT EFFICIENCY OF DIFFERENT IRRIGATING PROTOCOLS IN TRUSS CAVITY ACCESS PREPARATION
}

\author{
Hajer M. Abd Elhamid*
}

\begin{abstract}
Minimal invasive dentistry is our goal to preserve the tooth structure. In this era the revolution in technological advances used in endodontic treatment such as digital radiographic imaging, operating microscopes, newly-designed endodontic access burs, heat treated rotary nickel-titanium root canal instruments, ultrasonic irrigation, negative pressure irrigation could enable the application of conservative endodontic access (CEC) cavity preparations. This is done to conserve tooth structure, especially chamber roof and peri-cervical dentine, challenges to clinicians of working effectively in confined spaces, and avoiding procedural complications, while lacking a convenient form, also biological (debridement) aspects have not been investigated. This study compared and evaluated the cleanliness efficiency of different irrigating systems in CEC.
\end{abstract}

Methods: Eighty sound upper first premolars extracted due to orthodontic treatment were used in this study after taking pre-instrumentation digital x-ray using RVG to confirm the number of root canals and exclude any tooth with anatomical abnormality. The teeth were randomly divided into 4 groups $(\mathrm{n}=20)$ in each according to the irrigation protocol $(\mathrm{G} 1$ : Conventional method with Irriflex irrigating needle); (G2: ENDOVAC negative pressure irrigation system); (G3: PUI with ED62 irrigation ultrasonic tip); (G4: Er,Cr:YSGG Laser SWEEPS Mode). Conservative access preparation was done under high magnification. After instrumentation with M3 Pro Gold rotary file to a size 35/0.04 taper and irrigated, specimens were examined under SEM, and cleanliness of pulp chamber and root canal walls at coronal, middle, apical thirds was measured. Data were measured, tabulated and statistically analyzed by ANOVA and t-student test $(\mathrm{P}<0$.05).

Results: Group1 showed the highest smear layer scores at both apical and pulp chamber areas with no significant differences between all areas of the root canal and the pulp chamber. At the apical third of the root canal and the pulp chamber area, there was no significant difference between G2 (EndoVac) and G1 (IrriFlex) in smear layer elimination from root canal dentin wall. However, the least amount of smear layer and maximum number of open dentinal tubules was in G4 at all levels of the root canals and pulp chamber with no significant differences between G4 (Er,Cr:YSGG Laser) and G3 (PUI) showing the maximum cleanliness among all irrigation protocols compared to G1 and G2. There were no significant differences between all areas of the root canal and the pulp chamber in $\mathrm{G} 3$ and $\mathrm{G} 4$.

Conclusions: debridement of the pulp chamber and root canals were significantly possible in CEC using new irrigation methods as Er,Cr:YSGG laser and PUI.

KEYWORDS Contracted endodontic access, Irriflex, passive ultrasonic irrigation, Er;Cr: YSGG laser, ENDOVAC, truss access approach, orifice-directed access.

* Lecturer of Endodontics, Endodontic Department, MTI University. 


\section{INTRODUCTION}

Straight-line access to the root canals is the main objective of adequate endodontic access cavity. Traditional endodontic access cavity (TEC) design includes pulp horns and complete deroofing to achieve adequate debridement of the root canal ${ }^{(1,2)}$. The access cavity preparation depends on the G.V. Black's principles. 'Extension for prevention,' is the major concept that has been followed universally for many decades ${ }^{(3)}$. Clark and Khademi demonstrated a new approach with contracted endodontic cavity design CEC. This technique preserve the pericervical dentin and assume that complete deroofing of the pulp chamber was not important ${ }^{(4-6)}$. CEC has an approach of the orifice-directed design called the "truss" access cavity in which separate orifice cavities are prepared directed to the canals in upper and lower teeth ${ }^{(7)}$.

Studies showed that TEC has significantly higher percentage of teeth distruction due to convenience form of access endodontic cavity compared with contracted access cavity preparation (Truss cavity design $)^{(8,9)}$. However, many studies reported and concluded that the conservative access cavity is preferable in the mechanical properties ${ }^{(10-11)}$. The primary and important objective of "Truss access cavity designs" is strategic dentin preservation (i.e, leaving a truss of dentin between the 2 cavities thus prepared) ${ }^{(12-13)}$. Scientific data regarding the degree of debridement in (CEC) designs are not available although there have been some reports evaluating the advantages of mechanical aspects of "minimally invasive access cavities" (14).

This study was conducted to examine if the "Truss access design" holds a significant possibility to achieve adequate removal of pulp tissues and necrotic debris and optimum debridement to the pulp chamber and root canals. It is not known if the ability to debride the pulp chamber and root canal system might be influenced by an access cavity based on orifice- directed dentin conservation (DDC) Truss cavity. The aim of this study was to evaluate debridement efficiency of different irrigating protocols and systems in orifice directed dentin conservation (DDC) access cavity designs (Truss cavity) in the upper first premolar teeth using scanning electron microscope (SEM).

\section{MATERIALS AND METHODS}

\section{Selection of Teeth}

Eighty sound extracted upper first premolars due to orthodontic treatment were used in this study after taking pre-instrumentation digital $\mathrm{x}$-ray using RVG (Vatech, Korea) to confirm the number of root canals and exclude any tooth with anatomical abnormality (15). The teeth were divided randomly into 4 groups $(\mathrm{n}=20)$ in each according to the irrigation protocol (G1: Conventional method with Irriflex irrigating needle) ;( G2: ENDOVAC negative pressure irrigation system); (G3: PUI with ED62 irrigation ultrasonic tip); (G4: Er,Cr:YSGG Laser SWEEPS Mode). Teeth were preserved in vials containing 5 $\mathrm{mL} 10 \%$ formalin until use.

\section{Access Cavity Preparation}

Access preparation was done under high magnification using dental operating microscope DOM (Zeiss Meditec; Dublin, CA) to affords superior vision, while providing options in magnification and coaxial lighting during endodontic access preparation ${ }^{(16)}$. DDC access cavity were done as rounded cavities which were performed over the buccal and palatal pulp horns of the tooth, at the middle of the buccal and palatal occlusal slob of the buccal and palatal cusp (Fig. 1). The access to pulp chamber was gained from occlusal surface to roof of the pulp chamber by orienting the bur parallel to the long axis of the tooth in rounded shape with a small round bur (Mani Inc. bur size no \#2) in a high-speed handpiece with water cooling.. The pulp chamber roof was intact between the buccal and palatal access cavities in the "truss" of the tooth structure (Fig. 2). Maxillary premolars with nearly similar dimensions were selected to gain some degree of standardization. 


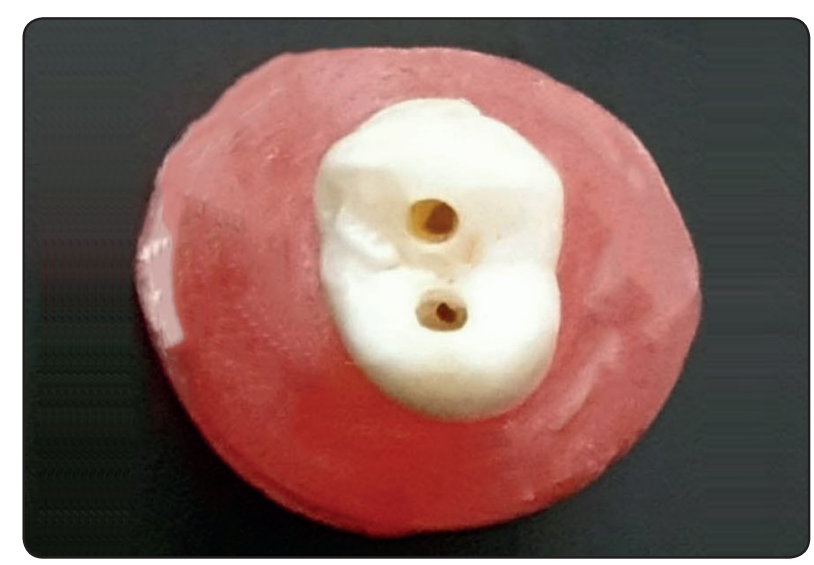

Fig. (1) Orifice- directed dentin conservation (DDC) "Truss cavity"

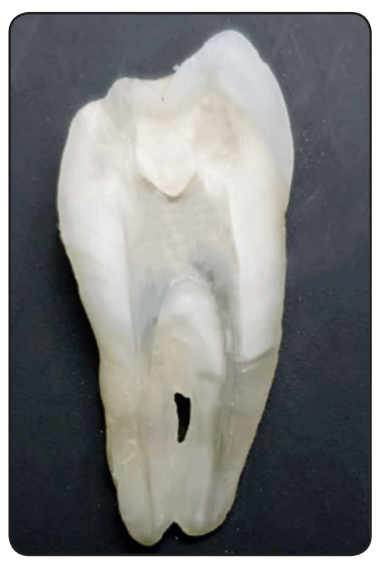

Fig. (2) The pulp chamber roof maintained below the "truss" of the tooth structure between the buccal and palatal cavities

\section{Root Canal Preparation}

Patency was established with a pre-curved, K-file size \#10 (Dentsply/ Maillefer) using a watchwinding motion until it reaches the root apex. The working length of the root canals were determined with size 15 stainless steel hand files. All the root canals were instrumented to a size 35/0.04 taper using M3 Pro Gold (United Dental, Shanghai, China) (CM Wire) nickel-titanium rotary instruments ${ }^{(17,18)}$. The irrigation parameters (volume and duration) were standardized between the groups with different irrigation protocols ${ }^{(19)}$. During instrumentation, $3 \mathrm{~mL} 5.25 \%$ sodium hypochlorite per canal at a flow rate of $1.5 \mathrm{~mL} / \mathrm{min}$ was delivered between each instrument. . A size $10 \mathrm{~K}$-file was used to maintain apical patency. (Fig . 3)
For G1: Conventional method with Irriflex irrigating needle (Products Dentaires SA (PD), Vevey, Switzerland) its 30 gauge soft polypropylene needle curve and flex easily in complex root canal anatomies, $4 \%$ taper, solution activation with back and forth movements, Back-to-back 2-side vent design to secure a balanced irrigation volume and a better control on the root canal irrigation. The needle is introduced $1 \mathrm{~mm}$ from the working length.

\section{For G2: ENDOVAC negative pressure irrigation} system (Discus Dental Smart Endodontics, USA) using the macro and micro canula 28gauge needle $(0.32 \mathrm{~mm})$ with 12 laser-drilled, microscopic evacuation holes - each less than 100 microns in size - placed at the end of the needle. Fluid is drawn to the apical termination through these holes, creating a vortex-like cleaning of the apical third during instrumentation of each root canal.

For G3: PUI with ED62 irrigation ultrasonic tip (Satelec, Woodpecker, Merignac, France). Used at power level 5 after placing the irrigation solution for activation of irrigation

For G4: Er,Cr:YSGG Laser SWEEPS Mode (Shock Wave Enhanced Emission Photoacoustic Streaming) modality for Er,Cr:YSGG laser (Waterlase iplus, Biolase, Germany) to improve the cleaning and disinfecting efficacy of laser-assisted endodontic procedures. Parameters used power 0.75 W, Pulse rate $20 \mathrm{~Hz}$, Air 10\%, H mode and RFT2.

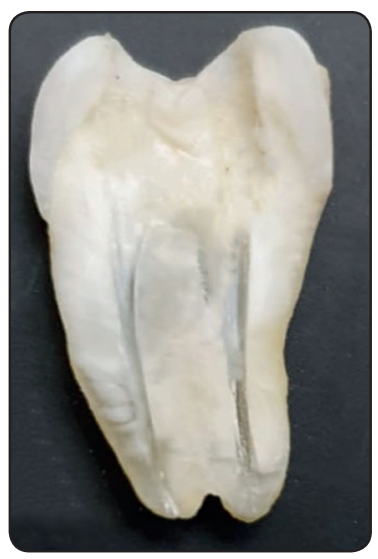

Fig. (3) Root canals after final irrigation and instrumentation to size 35/0.04 taper using "M3ProGold Ni-Tirotary" 
An acceleration of collapse of the laser-induced bubbles is achieved, leading to the emission of shock waves into narrow root canals. The emitted primary shock waves at super-sonic speeds and the shear flows created by the fast collapse of secondary bubbles near the canal walls enhance the cleaning and disinfecting efficacy of laser induced irrigation.

All root canals received a final rinse summarized in (Table 1). $5 \mathrm{~mL} 5.25 \%$ sodium hypochlorite at a standard flow rate of $1.5 \mathrm{~mL} / \mathrm{min}$ then the canals were irrigated with $2 \mathrm{~mL}$ distilled water over a period of $1 \mathrm{~min}$ then $3 \mathrm{ml}$ of $17 \%$ EDTA delivered over a period of $1 \mathrm{~min}$ finally $2 \mathrm{~mL}$ distilled water over a period of $1 \mathrm{~min}$ was done. Canals were dryed with absorbent paper points.

Cleanliness evaluation using Scanning Electron Microscope

After root canal instrumentation and performing irrigation protocol to different groups, the teeth were sectioned or split longitudinally into two halves using discs and chisel. Five samples from each group for evaluation of cleanliness of canal walls were randomly selected. One of the halves of each tooth was selected for examination under scanning electron microscope (SEM) after gold sputtering at the area of pulp chamber and root canals under 1200x magnification for debris and smear layer evaluation. The cleanliness of each root canal was evaluated in three areas apical, middle and coronal thirds of the root by using software analysis program (Image J -1.31v, USA).

The measurement of the amount of debris was done by transferring the scanning electron microscope images into the computer and the software measures the surface area occupied by the debris compared to the total area of the image. This gave us a ratio between the area of debris to the total area then the percentage of canal cleanliness in all segments of the root canals. Data were measured, tabulated and statistically analyzed by ANOVA test and $\mathrm{t}$-student test

\section{Smear layer}

- Score 1: All dentinal tubules are open and no smear layer present.

- Score 2: Some dentinal tubules are open and others covered by a thin smear layer.

- Score 3: A few dentinal tubules are open and others covered bya thin homogenous smear layer.

TABLE (1) Final rinse Irrigation Protocols Used in Truss cavity

\begin{tabular}{|c|c|c|c|c|c|}
\hline Groups & $\begin{array}{l}\text { Device used and } \\
\text { parameters }\end{array}$ & Step 1 & Step 2 & Step 3 & Step 4 \\
\hline G1 & $\begin{array}{l}\text { Conventional method } \\
\text { with Irriflex irrigating } \\
\text { needle }\end{array}$ & $\begin{array}{l}5 \mathrm{~mL} 5.25 \% \mathrm{NaOCl} \\
\text { delivered at flow rate of } \\
1.5 \mathrm{ml} / \mathrm{min}\end{array}$ & $\begin{array}{l}2 \mathrm{~mL} \text { distilled } \\
\text { water over a } \\
\text { period of } 1 \mathrm{~min}\end{array}$ & $\begin{array}{l}3 \mathrm{~mL} \text { of } 17 \% \text { EDTA } \\
\text { delivered over a } \\
\text { period of } 1 \mathrm{~min}\end{array}$ & $\begin{array}{l}2 \mathrm{~mL} \text { distilled } \\
\text { water over a } \\
\text { period of } 1 \mathrm{~min}\end{array}$ \\
\hline $\mathrm{G} 2$ & $\begin{array}{l}\text { ENDOVAC negative } \\
\text { pressure irrigation } \\
\text { system }\end{array}$ & $\begin{array}{l}5 \mathrm{~mL} 5.25 \% \mathrm{NaOCl} \\
\text { delivered at flow rate of } \\
1.5 \mathrm{ml} / \mathrm{min}\end{array}$ & $\begin{array}{l}2 \mathrm{~mL} \text { distilled } \\
\text { water over a } \\
\text { period of } 1 \mathrm{~min}\end{array}$ & $\begin{array}{l}3 \mathrm{~mL} \text { of } 17 \% \text { EDTA } \\
\text { delivered over a } \\
\text { period of } 1 \mathrm{~min}\end{array}$ & $\begin{array}{l}2 \mathrm{~mL} \text { distilled } \\
\text { water over a } \\
\text { period of } 1 \mathrm{~min}\end{array}$ \\
\hline G3 & $\begin{array}{l}\text { PUI with ED62 } \\
\text { irrigation ultrasonic tip }\end{array}$ & $\begin{array}{l}5 \mathrm{~mL} 5.25 \% \mathrm{NaOCl} \\
\text { delivered at flow rate of } \\
1.5 \mathrm{ml} / \mathrm{min}\end{array}$ & $\begin{array}{l}2 \mathrm{~mL} \text { distilled } \\
\text { water over a } \\
\text { period of } 1 \mathrm{~min}\end{array}$ & $\begin{array}{l}3 \mathrm{~mL} \text { of } 17 \% \text { EDTA } \\
\text { delivered over a } \\
\text { period of } 1 \mathrm{~min}\end{array}$ & $\begin{array}{l}2 \mathrm{~mL} \text { distilled } \\
\text { water over a } \\
\text { period of } 1 \mathrm{~min}\end{array}$ \\
\hline G4 & $\begin{array}{l}\text { Er,Cr:YSGG Laser } \\
\text { SWEEPS Mode }\end{array}$ & $\begin{array}{l}5 \mathrm{~mL} 5.25 \% \mathrm{NaOCl} \\
\text { delivered at flow rate of } \\
1.5 \mathrm{ml} / \mathrm{min}\end{array}$ & $\begin{array}{l}2 \mathrm{~mL} \text { distilled } \\
\text { water over a } \\
\text { period of } 1 \mathrm{~min}\end{array}$ & $\begin{array}{l}3 \mathrm{~mL} \text { of } 17 \% \text { EDTA } \\
\text { delivered over a } \\
\text { period of } 1 \mathrm{~min}\end{array}$ & $\begin{array}{l}2 \mathrm{~mL} \text { distilled } \\
\text { water over a } \\
\text { period of } 1 \mathrm{~min}\end{array}$ \\
\hline
\end{tabular}


- Score 4: All dentinal tubules are covered by a homogenous smear layer without any open tubules visible.

- Score 5: Thick homogenous layer completely covering the canal walls.

\section{RESULTS}

The cleanliness of canals walls was evaluated through scanning electron microscope (SEM) after gold sputtering. [Table: 1] shows mean and standard deviation of smear layer scoring for the four groups at coronal, middle, apical third of the root canal and the pulp chamber. Group1 shows the highest smear layer scores at both apical and pulp chamber area with no significant differences between all areas of the root canal and the pulp chamber. At the apical third of the root canal and the pulp chamber area, there was no significant difference between G2 (EndoVac) and G1 (IrriFlex) in removal of smear layer from root canals . However, the least amount of smear layer and maximum number of open dentinal tubules were in G4 at all levels of the root canals and pulp chamber with no significant differences between G4 (Er,Cr:YSGG Laser) and G3 (PUI) showing the maximum cleanliness among all irrigation protocols compared to $\mathrm{G} 1$ and G2 [Table:2]. There were no significant differences between all areas of the root canal and the pulp chamber in G3 and G4. (Fig . 4)

TABLE (2) Mean and standard deviation of smear layer score at pulp chamber and coronal, middle, apical thirds of the root canal in groups $1,2,3,4$

\begin{tabular}{|l|c|c|c|c|}
\hline Group & Pulp Chamber & Coronal third & Middle third & Apical third \\
\hline & Mean +/- SD & Mean +/- SD & Mean +/- SD & Mean +/- SD \\
\hline G1 & $4.15+/-0.67$ & $3.95+/-0.6$ & $4+/-0.64$ & $4.2+/-0.69$ \\
\hline G2 & $4+/-0.45$ & $3.75+/-0.55$ & $3.9+/-0.55$ & $4.1+/-0.71$ \\
\hline G3 & $1.5+/-0.61$ & $1.3+/-0.47$ & $1.2+/-0.41$ & $1.35+/-0.48$ \\
\hline G4 & $1.15+/-0.36$ & $1.05+/-0.22$ & $1.1+/-0.31$ & $1.15+/-0.36$ \\
\hline
\end{tabular}

G1: Conventional method with Irriflex irrigating needle, G2: ENDOVAC negative pressure irrigation system, G3: PUI with ED62 irrigation ultrasonic tip, G4: Er,Cr:YSGG Laser SWEEPS Mode

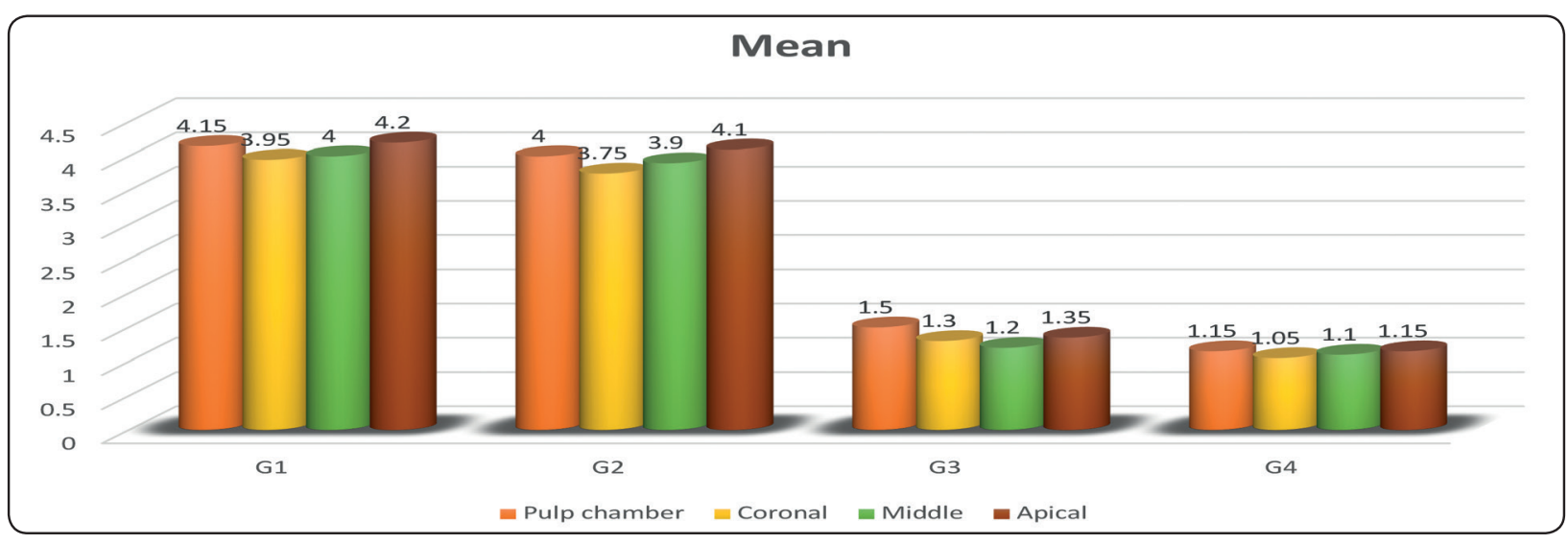

Fig. (4) Chart shows mean of smear layer at pulp chamber and coronal, middle, apical thirds of the root canal in G1: Conventional method with Irriflex irrigating needle, G2: ENDOVAC, G3: PUI, G4: Er,Cr:YSGG Laser 

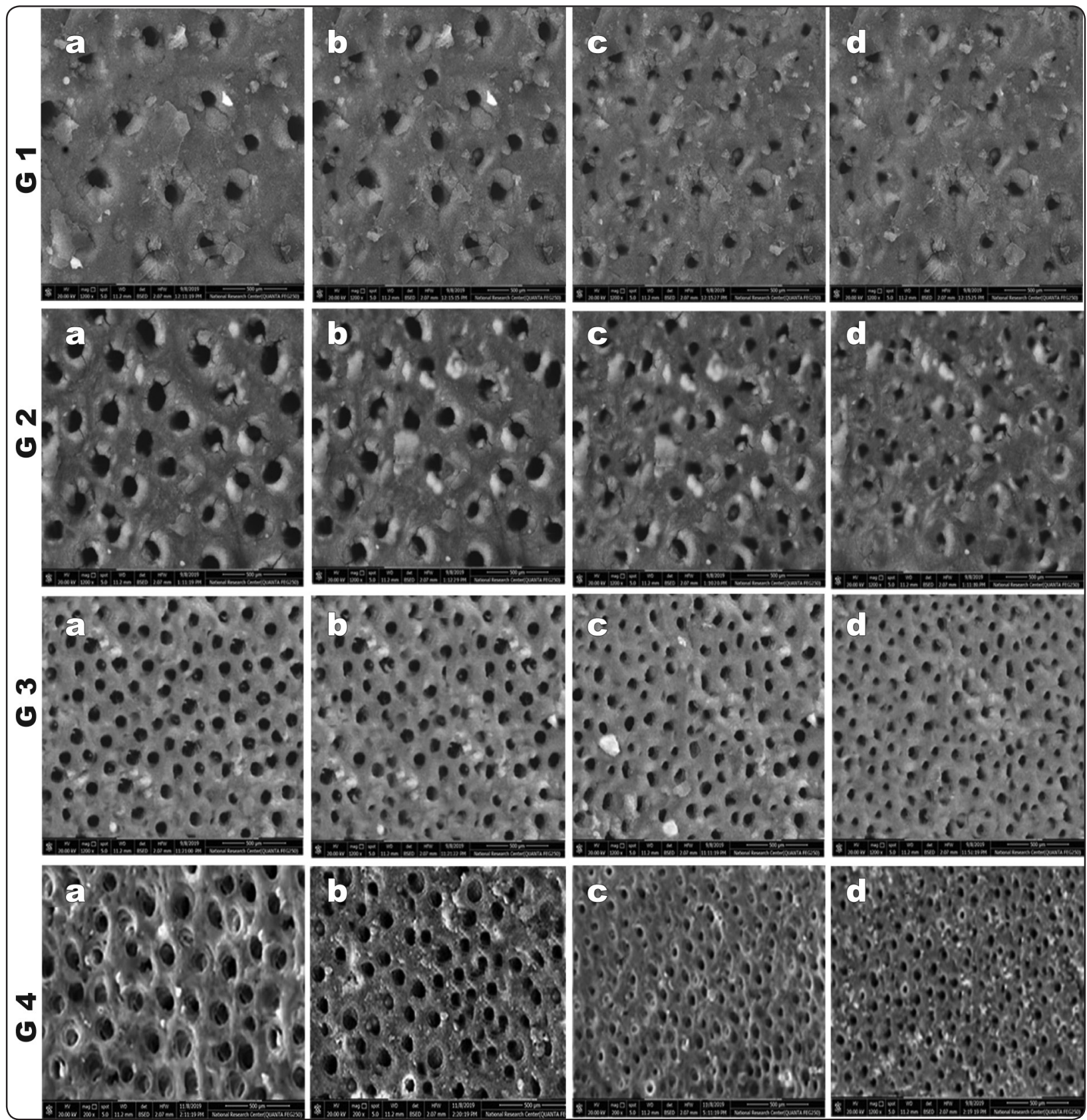

Fig. (5) Scanning electron micrograph under magnification of 1200X showing the open dentinal tubules using different irrigation systems in G1: Conventional method with Irriflex irrigating needle, G2: ENDOVAC, G3: PUI, G4: Er,Cr:YSGG Laser at pulp chamber (a), coronal third of root canal (b), middle third (c), apical third (d) 


\section{DISCUSSION}

One of the most important factors in conservative endodontic treatment is the conservation of tooth structure which affects the survival of endodontically treated teeth. The benefits and possible drawbacks of the conservative endodontic access cavity concept have not been well supported by research data. Root canal treatment mainly relies on complete cleaning and disinfection of root canals and filling it with biologically compatible materials ${ }^{[19]}$. A little modification of the principles which include the outline form, the convenience form, removal of the carious dentin has been tried in contrast of the principles is Black's concept of 'extension for prevention', which promotes the sacrifice of additional tooth structure to prevent iatrogenic complications and to best achieve the ultimate goals. To overcome the problem of preservation of tooth structure especially pericervical dentin, different conservative access cavity designs came into existence ${ }^{[8]}$. There are different debates for the concept of CEC (ultraconservative "Ninja" and orifice-directed "Truss" access) ${ }^{[5]}$.

However, a major drawback is that there is a lack of evidence to support the use of Truss access cavity preparation which can be used as an alternative method to traditional access cavities on a daily basis ${ }^{[20]}$. In a study conducted by Corsentino et al. ${ }^{(21)}$ concluded that TRECs do not increase the fracture strength of endodontically treated teeth in comparison with CECs and TECs. Plotino et al., (22) examined maxillary and mandibular premolar teeth with TEC access which showed lower fracture strength than the ones prepared with CEC or NEC. This is the first known case series where Truss access was used and the first case report where Truss access was used on maxillary premolars ${ }^{(6)}$. The approach of creating a Truss access was performed according to the diagrammatic representation which was used in a study performed by Neelakattan et al. ${ }^{(23)}$. In a study performed by Ozyurk et al. CEC preparation did not increase the fracture strength of teeth with class II cavities compared with TEC preparation ${ }^{(24)}$. One of the major disadvange in Truss access is inaccuracy which may lead to gouging and worst may even lead to perforation, missed canals ${ }^{(25)}$. Despite the limited evidence on the great different among the philosophies designs of contracted access cavity and the increasing interest, many technological advances in imageguided endodontics may improve the root canal treatment and make a great shift ${ }^{(26,27)}$. Thus, clinical experience and proper radiographic assessment is necessary while planning a Truss access.

In the literature, there is no sufficient evidence in accepting or refusing the philosophy of contracted endodontic access cavity design based on the effect of such designs on the cleanliness of pulp chamber and root canal dentin walls ${ }^{(28)}$. This study evaluated the cleanliness of pulp chamber and root canals in orifice-directed approach "Truss" access using different irrigation systems.

Scanning electron microscope is an accepted and accurate method to evaluate the debridement efficacy and cleanliness after root canal instrumentation using rotary $\mathrm{Ni}-\mathrm{Ti}$ instruments enlarged to size 35 / 0.04 and irrigation strategies. Remnants of pulp tissue might be a port to microbes serving as a source of nutrition, resulting in root canal persistent infection thus adequate and complete removal of pulp tissue and the micro-organisms from the root canal system is a must. Another related factor is the apical preparation diameters and the accessibility of irrigants to the apical portion of the canals and the lateral and accessory canals, in addition to the irrigation protocol as volume, concentration, duration, and irrigant activation ${ }^{(29-34)}$.

Improvement and advances in irrigation systems and strategies may result in better adequate debridement and removal of remnants of pulp tissue than the conventional syringe irrigation ${ }^{(35,36)}$ especially in root canal cleanliness of the DDC access cavity "Truss" access. This might be in close 
relation to insufficient generation of hydrodynamic shear stress by conventional syringe and needle irrigation (37,38). In "activation/agitation" strategy there is no analysis was done to determine if the cleanliness of the pulp chamber and root canals of DDC access cavities can be improved by this methods.

Removal of smear layer is a benchmark for cleanliness of root canal walls. Wu et al. ${ }^{(39)}$ showed that the smear layer removal ability of $17 \%$ EDTA was significantly better than other chelating agents. Dai et al. ${ }^{(40)}$ revealed that Q-Mix was as effective as $17 \%$ EDTA in removing canal wall smear layers after the use of $5.25 \% \mathrm{NaOCl}$ as the initial rinse which dissolve necrotic tissue, vital pulp tissue, organic components in dentin and bacterial biofilm. Rödig et al. ${ }^{(41)}$ confirmed the irrigation efficacy of EDTA for $1 \mathrm{~min}$ in removing the smear layer and prevent decalcification effect . Caron et al. ${ }^{(42)}$ revealed that although 17\% EDTA 3\% $\mathrm{NaOCl}$ removing the smear layer, sonic and ultrasonic activation improved the efficacy of the mentioned combination in removing the smear layer. Irrigation with saline between $\mathrm{NaOCl}$ and EDTA is essential because EDTA stops the tissue dissolving capacity of $\mathrm{NaOCl}{ }^{(43)}$

Caron $G$ et al (44) revealed that root canal cleanliness benefits increases from solutions activation (especially sonic activation and manualdynamic activation) in comparison with no activation during the final irrigation regimen. Caron $\mathrm{G}$ et al ${ }^{(45)}$ showed that PUI can be an important supplement for cleaning the root canal system and, compared with traditional syringe irrigation. It removes more organic tissue, planktonic bacteria and dentine debris from the root canal. Chen JE et al ${ }^{(46)}$ revealed that the apical negative pressure mode of irrigation ENDOVAC generated the lowest wall shear stress thus it doesn't remove debris effectively, while the passive-ultrasonic irrigation group showed the highest wall shear stress along with the greatest magnitude of velocity.
Wang et al ${ }^{(47)}$ revealed that laser activations (Er,Cr:YSGG) significantly enhanced the effect of the $\mathrm{NaOCl}$, EDTA, irrigations in removing smear layer from dentin walls. As Naashari et al (48) confirms that maximum effect is obtained when laser light is used in canals in combination with sodium hypochlorite irrigating substance in appropriate concentration. Therefore use of laser energy can improve success rate of root canal treatments.

The results of this study yielded two important findings: Er,Cr:YSGG Laser with SWEEPS Mode (Shock Wave Enhanced Emission Photoacoustic Streaming) modality improves the cleaning and disinfecting efficacy of laser-assisted endodontic procedures and has the least amount of smear layer and maximum number of open dentinal tubules at all levels of the root canals and pulp chamber with no significant differences between it and (PUI). Activation/agitation strategy improves the efficiency of irrigants in pulp chamber and root canal debridement of DDC access cavities.

\section{CONCLUSION}

Debridement of the pulp chamber and root canals was significantly possible in DDC using new irrigation methods as Er,Cr:YSGG laser and PUI.

\section{REFERENCES}

1. Ingle JI. Endodontic cavity preparation. In: Ingle J, Tamber J, eds. Endodontics, 3rd

2. Narayana P. Access cavity preparations. In: Schwartz RS, Canakapalli V. Best Practices in Endodontics: A Desk Reference, 1st ed. Chicago, IL: Quintessence Publishing; 2015:89-104

3. Patel S, Rhodes J. A practical guide to endodontic access cavity preparation in molar teeth. Br Dent J 2007; 203:133-40

4. Clark D, Khademi J. Modern endodontic access and dentin conservation, part 2. Dent Today. 2009 Nov; 28(11):86- 90

5. Clark D, Khademi J. Modern molar endodontic access and directed dentin conservation. Dent Clin North Am . 2010; $54: 249-273$ 
6. Clark D, Khademi JA. Case studies in modern molar endodontic access and directed dentin conservation. Dent Clin North Am . 2010; 54:275 -289.

7. Clark D, Khademi J. Modern endodontic access and dentin conservation, part 1. Dent Today 2009 Oct ;28:86-90.

8. Boveda C, Kishen A. Contracted endodontic cavities: the foundation for less invasive alternatives in the management of apical periodontitis. Endod Topics 2015; 33:169-86.

9. Bürklein S, Schäfer E. Minimally invasive endodontics, Quintessence Int 2015:46:119-124.

10. Clark D, Khademi J, Herbranson E. Fracture resistant endodontic and restorative preparations. Dent Today . 2013; 32:118.

11. Clark D, Khademi J, Herbranson E. The new science of strong endo teeth. Dent Today . 2013; 32:112.

12. Bassir MM, Labibzadeh A, Mollaverdi F. The effect of amount of lost tooth structure and restorative technique on fracture resistance of endodontically treated premolars. J Conserv Dent . 2013; 16:413 - 7 .

13. Scientific data regarding the degree of debridement in contracted endodontic access cavity (CEC) designs are absent although there have been some reports addressing the mechanical aspects of minimally invasive access cavities (12-16).

14. Moore B, Verdelis K, Kishen A, Dao T, Friedman S. Impacts of contracted endodontic cavities on instrumentation efficacy and biomechanical responses in maxillary molars. J Endod . 2016; 42:1779 -83.

15. Benenati FW, Khajotia SS. A radiographic recall evaluation of 894 endodontic cases treated in a dental school setting. J Endod 2002;28:391-5.

16. Ahmed HM. A paradigm evolution shift in the endodontic map. Eur J Gen Dent 2015;4:98.

17. Aminoshariae A, Kulild JC. Master apical file size - smaller review of healing outcomes. J Endod 2015;41:999-1007.

18. Aminoshariae A, Kulild JC. Master apical file size - smaller review of microbial reduction. J Endod 2015;48:1007-22.

19. Neelakantan P, Devaraj S, Jagannathan N. Histologic assessment of debridement of the root canal isthmus of mandibular molars by irrigant activation techniques ex vivo. J Endod 2016;42:1268-72.

20. Abou -Elnaga MY, Alkhawas MB, Kim HC, Refai AS. Effect of Truss Access and Artificial Truss Restoration on the Fracture Resistance of Endodontically Treated
Mandibular First Molars. Journal of endodontics. 2019; 45(6):813 -7.

21. Corsentino G, Pedullà E, Castelli L, Liguori M, Spicciarelli V, Martignoni M, Ferrari M, Grandini S. Influence of access cavity preparation and remaining tooth substance on fracture strength of endodontically treated teeth. Journal of endodontics. 2018; 44(9):1416 - 21.

22. Plotino G, Grande NM, Isufi A, Ioppolo P, Pedullà E, Bedini R, Gambarini G, Testarelli L. Fracture strength of endodontically treated teeth with different access cavity designs. Journal of endodontics. 2017 ; 43(6):995 -1000.

23. Neelakantan P, Khan K, Ng GP, Yip CY, Zhang C, Cheung GS. Does the orifice -directed dentin conservation access design debride pulp chamber and mesial root canal systems of mandibular molars similar to a traditional access design? Journal of endodontics. 2018 ; 44(2):274 - 9.

24. Özyürek T, Ülker Ö, Demiryürek EÖ, Yılmaz F. The effects of endodontic access cavity preparation design on the fracture strength of Endodontically treated teeth: traditional versus conservative preparation. Journal of endodontics. 2018; 44(5):800 -5.

25. Saygili G, Uysal B, Omar B, Ertas ET, Ertas H. Evaluation of relationship between endodontic access cavity types and secondary mesiobuccal canal detection. BMC Oral Health. 2018 Jul 6;18(1):121.

26. Varghese VS, George JV, Mathew S, Nagaraja S, Indiresha HN, Madhu KS. Cone beam computed tomographic evaluation of two access cavity designs and instrumentation on the thickness of peri-cervical dentin in mandibular anterior teeth.J Conserv Dent. 2016 Sep-Oct;19(5):450-4.

27. Connert T, Zehnder MS, Weigner R, et al. Microguided endodontics: accuracy of a miniaturized technique for apically extended access cavity preparation in anterior teeth. J Endod 2017;43:787-90.

28. Seixas FH, Estrela C, Bueno MR, Sousa-Neto MD, Pécora JD. Determination of Root Canal Cleanliness by Different Irrigation Methods and Morphometric Analysis of Apical Third. J Contemp Dent Pract. 2015 Jun 1;16(6):442-50.

29. Siqueira JF Jr, Pérez AR, Marceliano-Alves MF, Provenzano JC, Silva SG, Pires FR, Vieira GCS, Rôças IN, Alves FRF. What happens to unprepared root canal walls: a correlative analysis using micro-computed tomography and histology/scanning electron microscopy. Int Endod J. 2018 May;51(5):501-508. 
30. Da Silva JM, Silveira A, Santos E, Prado L, Pessoa OF. Efficacy of sodium hypochlorite, ethylenediaminetetraacetic acid, citric acid and phosphoric acid in calcium hydroxide removal from the root canal: a microscopic cleanliness evaluation.Oral Surg Oral Med Oral Pathol Oral Radiol Endod. 2011 Dec;112(6):820-4.

31. Lipski M, Lichota D, Górski M, Dura W, Droździk A Cleanliness of the walls of root canals in teeth with incomplete development of root, rinsed with $2 \%$ chlorexidine. A SEM study.Ann Acad Med Stetin. 2013;59(2):81-5.

32. Susin L, Liu Y, Yoon JC, et al. Canal and isthmus debridement efficacies of two irrigant agitation techniques in a closed system. Int Endod J 2010;43:1077-90.

33. Trope M, Bergenholtz G. Microbiological basis for endodontic treatment: can a maximal outcome be achieved in one visit? Endod Topics 2002;1:40-53.

34. Khademi A, Yazdizadeh M, Feizianfard M. Determination of the minimum instrumen- tation size for penetration of irrigants to the apical third of root canal systems. J Endod 2006;32:417-20.

35. Setlock J, Fayad MI, BeGole E, Bruzick M. Evaluation of canal cleanliness and smear layer removal after the use of the Quantec-E irrigation system and syringe: a comparative scanning electron microscope study.Oral Surg Oral Med Oral Pathol Oral Radiol Endod. 2003 Nov; 96(5):614-7.

36. Haapasalo M, Shen Y, Wang Z, Gao Y. Irrigation in endodontics.Br Dent J. 2014 Mar;216(6):299-303.

37. Li D, Jiang S, Yin X, Chang JW, Ke J, Zhang C. Efficacy of Needle, Ultrasonic, and Endoactivator Irrigation and Photon-Induced Photoacoustic Streaming in Removing Calcium Hydroxide from the Main Canal and Isthmus: An In Vitro Micro-Computed Tomography and Scanning Electron Microscopy Study.Photomed Laser Surg. 2015 Jun;33(6):330-7.

38. Susila A, Minu J. Activated Irrigation vs. Conventional non-activated Irrigation in Endodontics - A Systematic Review. Eur Endod J. 2019 Nov 25;4(3):96-110.

39. Wu L, Mu Y, Deng X, Zhang S, Zhou D. Comparison of the effect of four decalcifying agents combined with $60^{\circ} \mathrm{C}$
$3 \%$ sodium hypochlorite on smear layer removal. J Endod. 2012;38:381-4

40. Dai L, Khechen K, Khan S, Gillen B, Loushine BA, Wimmer CE, et al. The effect of QMix, an experimental antibacterial root canal irrigant, on removal of canal wall smear layer and debris. J Endod. 2011;37:80-4.

41. Rödig T, Döllmann S, Konietschke F, Drebenstedt S, Hülsmann M. Effectiveness of different irrigant agitation techniques on debris and smear layer removal in curved root canals: A scanning electron microscopy study. J Endod. 2010;36:1983-7.

42. Caron G, Nham K, Bronnec F, Machtou P. Effectiveness of different final irrigant activation protocols on smear layer removal in curved canals. J Endod. 2010;36:1361-6

43. M Grawehr 1, B Sener, T Waltimo, M Zehnder Interactions of Ethylenediamine Tetraacetic Acid With Sodium Hypochlorite in Aqueous Solutions Int Endod J 2003 Jun;36(6):411-7.

44. Caron G, Nham K, Bronnec F, Machtou P. Effectiveness of different final irrigant activation protocols on smear layer removal in curved canals. J Endod. 2010 Aug; 36(8):1361-6.

45. Van Der Sluis LW, Versluis M, Wu MK, Wesselink PR. Passive ultrasonic irrigation of the root canal: a review of the literature. Int Endod J. 2007 Jun; 40(6):415-26.

46. Chen JE, Nurbakhsh B, Layton G, Bussmann M, Kishen A. Irrigation dynamics associated with positive pressure, apical negative pressure and passive ultrasonic irrigations: a computational fluid dynamics analysis. Aust Endod J. 2014 Aug; 40(2):54-60

47. Wang X, Cheng X, Liu B, Liu X, Yu Q, He W. Effect of Laser-Activated Irrigations on Smear Layer Removal from the Root Canal Wall. Photomed Laser Surg. 2017 Dec; 35(12):688-694

48. Asnaashari M, Safavi N. Disinfection of Contaminated Canals by Different Laser Wavelengths, while Performing Root Canal Therapy. J Lasers Med Sci. 2013 Winter;4(1):8-16. 